J Medicine 2018; 19: 10-14

\title{
Detection of Precipitating Factors of Hepatic Encephalopathy in Chronic Liver Disease Patients in a Tertiary Hospital
}

\author{
MD. ASADUL KABIR, ${ }^{1} \mathrm{JEWEL} \mathrm{CHOWDHURY,}{ }^{2}$ MD. ANWARUL BARI, ${ }^{3} \mathrm{KAZI}$ BODRUDDOZA, ${ }^{4}$ ASIM KUMER SAHA, ${ }^{5}$ \\ SAYIK BIN ALAM 4
}

\begin{abstract}
:
Background: Chronic liver disease (CLD) is commonly encountered by physicians in hospital practice. Hepatic encephalopathy is a serious complication of chronic liver disease, arising most commonly in those with advanced liver cirrhosis. In patients with otherwise stable cirrhosis, hepatic encephalopathy often follows clearly identifiable precipitating events. The aim of study is to find out the precipitating factors and their frequency in patients of CLD presenting with hepatic encephalopathy to prevent mortality and morbidity.

Methods: This descriptive observational study was carried out to identify the precipitating factors and their frequency among 50 cases of diagnosed chronic liver disease presenting with hepatic encephalopathy at department of Medicine of Sir Salimullah Medical College \& Mitford hospital, Dhaka from July 2012 to December 2012 for a period of 6 months.

Results: Among 50 patients, 36 patients (72\%) were male, 14 (28\%) were female. Study showed that age frequency 14 (28\%) were from 41-50 years and 08 (16\%) were from 51-60 years, $12(24 \%)>60$ years of age. Out of 50 patients, the etiology of liver cirrhosis was hepatitis B virus in $28(56 \%)$, hepatitis C virus in 4 (8\%), both Hepatitis $B$ \& $C$ in 02 (4\%) Among 50 patients, 13 (26\%)were in Grade-3 and 11 (22\%) in Grade-2 Hepatic encephalopathy. According to Child-Pugh scoring 16 (32\%) in Grade-C \& 09 (18\%) in Grade-B. The most common precipitating factors were identified as GI bleeding (28\%), Infection (26\%), mixed (16\%) \& unknown (20\%). In this study, mortality rate was $32 \%$ most of the patients from Child-Pugh class-C.

Conclusions: Commonest precipitating factors of hepatic encephalopathy in this study were upper G.I. bleeding, infection, mixed factor and electrolyte imbalance. To prevent hepatic encephalopathy caution must be exercised in putting chronic liver disease patient on diuretics. Early and effective infection control measures and better hygienic conditions in government hospitals are needed to be maintained.
\end{abstract}

Keywords: Precipitating Factors, Hepatic Encephalopathy, Chronic Liver Disease.

\section{Introduction:}

Liver diseases affect millions of people worldwide each day. However, in the developing countries where cost of health care has always been an issue, long lasting diseases such as liver cirrhosis and its complications are a major

1. Associate Professor, Department of Medicine, SSMC \& MH, Dhaka.

2. Registrar, Department of Medicine, SSMC \& MH, Dhaka.

3. Assistant Professor, Department of Medicine, SSMC \& MH, Dhaka.

4. Honorary Medical Officer, Medicine Unit - VII, SSMC \& MH, Dhaka.

5. Assistant Registrar, Medicine Unit - VII, SSMC \& MH, Dhaka.

Corresponding author: Dr. Md. Asadul Kabir, Associate Professor, Department of Medicine, SSMC \& MH, Dhaka. health problem and pose a big challenge to the health economy. Because of poverty, poor hygienic conditions, inadequate education and lack of counseling, the number of cirrhotic patients is increasing and most of them are admitted to medical wards with different complications. ${ }^{1}$

The syndrome of hepatic encephalopathy (HE) describes all neuropsychiatric symptoms occurring in patients with acute or chronic liver diseases (CLD) in the absence of other neurological disorders. ${ }^{2}$

About $30 \%$ of patients with cirrhosis die in hepatic coma. ${ }^{3}$ Chronic liver disease patientis commonly encountered in our country due to high prevalence of hepatitis B and C infection. A report in 2008 showed $5.5 \% \mathrm{HbsAg}$ positivity among the general population living in Savar, a semi-urban area on the outskirts of Dhaka, Bangladesh. ${ }^{4}$ 
Appearance of HE (hepatic encephalopathy) in any patient is indicative of poor prognosis. ${ }^{5} \mathrm{HE}$ can occur either due to acute liver failure or due to one or more precipitating factors in a cirrhotic patient or it could happen as a result of prolonged portal systemic shunting resulting in a chronic portal systemic encephalopathy. ${ }^{6}$ Survival of patients having chronic porto-systemic encephalopathy is better than those who develop HE acutely $(100 \%$ vs. $70 \%){ }^{7}$ However prognosis in the latter group can be improved if the precipitating factors are recognized early and managed accordingly. ${ }^{8}$ Common precipitating factors include gastrointestinal bleeding, infection, azotemia, constipation, electrolyte imbalance and high protein diet. ${ }^{9}$ Usage of drugs such as sedatives, ${ }^{10}$ tranquilizers, analgesics and diuretics, fulminant hepatic injury, large volume paracentesis have all been considered to precipitate encephalopathy in an otherwise stable cirrhotic patient. Exact pathogenic mechanism involved is unknown till date, however the basic processes are failure of hepatic clearance of gut derived substances such as ammonia, free fatty acids, mercaptans etc., either through hepatocellular failure or shunting and altered amino acid metabolism, both of which result in changes in cerebral transmission causing depressed cerebral function. ${ }^{11}$ This study will aim at ascertaining the common precipitating factors and their frequency in patients presenting with hepatic encephalopathy.

\section{Methods:}

This was a descriptive observational study on 50 patients admitted into Medicine unit of Sir Salimullah Medical College \& Mitford Hospital, Dhaka from July 2012 to December, 2012. All adult patients admitted into Medicine unit, Sir Salimullah Medical College \& Mitford Hospital who have clinical, biochemical, sonological evidence chronic liver disease \& presents with features suggesting of hepatic encephalopathy or confusional state were included in this study. Patients were selected by purposive sampling method. Patients presenting with acute fulminant hepatic failure or patients who had clinical, biochemical and microbiological evidence of other causes of liver failure \& encephalopathy were excluded from the study. A data collection sheet was designed to record all the information of interest. A detailed clinical history of the patients was taken regarding the present and past illness. Question were asked about upper gastrointestinal bleeding, (hematemesis, melaena), constipation, high protein diet and usage of drugs such as diuretics, sedatives, analgesics, paracentesis and trauma or surgery. In some patients more than one risk factor was present (mixed factor). Special attention was given regarding presence of jaundice, anaemia, fever, asterisk and ascites. Encephalopathy was graded according to the criteria. For each patient full blood count, liver function test, renal function test, random blood sugar, serum electrolytes, serum albumin and coagulation profile were carried out. An abdominal ultrasound was done to look for liver \& spleen size, parenchymal echogenicity, and ascites. Any evidence of the presence of other co-existing complications of cirrhosis liver was also recorded and Child's Pugh score was assessed of each patient. All patients were followed for the duration of their stay in hospital. Participants were encouraged to take part in the study voluntarily. Consent was obtained after a brief of the study in Bengali was described to all respondents. Confidentiality was assured and anonymity maintained; special caution is taken that no participant can be identified in any report or publication under this study.

\section{Results:}

Total number of 50 patients was included in this study. The mean age of the study population is 44.3 years (SD 12.83 years) and $72 \%$ were male. Majority of the patients are Muslim and most female patient were house wife \& most of the patients come from low socioeconomic status (Table I). Mean age of patients was 44.3 years (STD-12.83). Maximum number of patients (14) in this study were in between 41-50 years age group followed by (12) $>60$ years age group \& 31-40 age group (Table II). 26 (52\%) patients were grade III encephalopathy, $11(22 \%)$ were in grade -IV, 9 (18\%) patients in grade- II and 4 (8\%) patients in grade - I encephalopathy (Figure 1). The etiology of chronic liver disease was hepatitis B virus in $28(56 \%)$, hepatitis $\mathrm{C}$ virus in 4 (8\%), Both HBV \& HCV in $2(4 \%)$, alcohol in $1(2 \%)$, Wilson Disease $1(2 \%)$ and others in 15 (30\%) patients (Table IV). All patients present with jaundice and ascites and 90\% patients present with splenomegaly (Table V). GI bleeding (28\%) and infection (26\%) were the most common precipitating factors of hepatic encephalopathy (Figure 2). In this study, mortality rate is $32 \%$, most of these due to Gastrointestinal Bleeding (57.14\%) (Table VI). 
Table-I

General characteristics of the whole study population

\begin{tabular}{|c|c|c|c|}
\hline \multicolumn{2}{|c|}{ Variables } & $\begin{array}{c}\text { Values } \\
\text { (Number/percentage) }\end{array}$ & SD \\
\hline \multicolumn{2}{|l|}{ Age } & 44.3 years & \pm 12.83 \\
\hline \multicolumn{4}{|l|}{ Sex } \\
\hline$\bullet$ & Male & $36(72 \%)$ & \\
\hline$\bullet$ & Female & $14(28 \%)$ & \\
\hline \multicolumn{4}{|c|}{ Religion } \\
\hline$\bullet$ & Muslim & $42(84 \%)$ & \\
\hline • & Hindu & $8(16 \%)$ & \\
\hline$\bullet$ & Others & $0(0 \%)$ & \\
\hline \multicolumn{4}{|c|}{ Occupation } \\
\hline \multicolumn{2}{|c|}{ - Service } & $6(12 \%)$ & \\
\hline \multicolumn{2}{|c|}{ - Business } & $14(28 \%)$ & \\
\hline \multicolumn{2}{|c|}{ - Housewife } & $13(26 \%)$ & \\
\hline \multicolumn{2}{|c|}{ - Others } & $17(34 \%)$ & \\
\hline
\end{tabular}

Table-II

Age distribution of patients $(n=50)$

\begin{tabular}{ccc}
\hline Age (Years) & No. of patient & SD \\
\hline$<20$ years & 2 & $4 \%$ \\
$20-30$ & 6 & $12 \%$ \\
$31-40$ & 8 & $16 \%$ \\
$41-50$ & 14 & $28 \%$ \\
$51-60$ & 8 & $16 \%$ \\
$>60$ & 12 & $24 \%$ \\
\hline
\end{tabular}

Figure 1:

Distribution of patients in different grades of hepatic encephalopathy

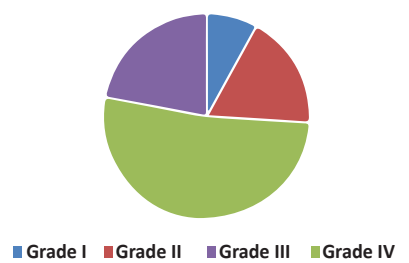

Table-III

Grading of patients according to Child Pugh's classification of cirrhosis

\begin{tabular}{ccc}
\hline Grade & Patients & Percentage \\
\hline B & 18 & $36 \%$ \\
C & 32 & $64 \%$ \\
\hline
\end{tabular}

Table-IV

Etiology of chronic liver disease

\begin{tabular}{lcc}
\hline Etiology & Frequency & Percentage \\
\hline HBV & 28 & $56 \%$ \\
HCV & 4 & $8 \%$ \\
Both B \& C & 2 & $4 \%$ \\
Wilson's & 1 & $2 \%$ \\
Alcohol & 1 & $2 \%$ \\
Unknown & 15 & $30 \%$ \\
Total & 50 & $100 \%$ \\
\hline
\end{tabular}

Table-V

Clinical presentations of patients with hepatic encephalopathy

\begin{tabular}{lcc}
\hline Sign/Symptom & Frequency & Percentage \\
\hline Jaundice & 50 & $100 \%$ \\
Hematemesis & 14 & $28 \%$ \\
Edema & 36 & $72 \%$ \\
Fever & 18 & $36 \%$ \\
Constipation & 12 & $24 \%$ \\
Ascites & 50 & $100 \%$ \\
Splenomegaly & 45 & $90 \%$ \\
PalmarErythema & 10 & $20 \%$ \\
\hline
\end{tabular}

Figure 2

Precipitating Factors of hepatic encephalopathy

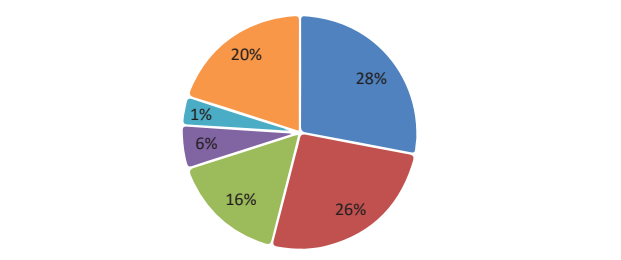

-Gl bleeding $\|$ Infection $=$ Mixed $=$ Hypokalemia $=$ Constipation $=$ Unknown

Table-VI

Outcome of patients according to Precipitating Factors

\begin{tabular}{llll}
\hline Risk Factor & $\begin{array}{c}\text { Survival } \\
(\% \text { of factor })\end{array}$ & $\begin{array}{c}\text { Death } \\
(\% \text { of factor })\end{array}$ & $\begin{array}{l}\text { Total Cases } \\
(\% \text { of total })\end{array}$ \\
\hline GI bleeding & $06(42.85 \%)$ & $08(57.14 \%)$ & $14(28 \%)$ \\
Infection & $11(84.62 \%)$ & $2(15.38 \%)$ & $13(26 \%)$ \\
Hypokalemia & $03(100 \%)$ & $0(0 \%)$ & $3(6 \%)$ \\
Constipation & $02(100 \%)$ & $0(0 \%)$ & $2(4 \%)$ \\
Mixed & $05(62.5 \%)$ & $03(37.5 \%)$ & $8(16 \%)$ \\
Unknown & $07(70 \%)$ & $03(30 \%)$ & $10(20 \%)$ \\
Total & $34(68 \%)$ & $16(32 \%)$ & $50(100 \%)$ \\
\hline
\end{tabular}




\section{Discussion:}

Chronic liver disease is one of the common causes of morbidity and mortality worldwide. Hepatic encephalopathy (HE) is a major neuropsychiatric complication of chronic liver disease and its appearance is indicative of a poor prognosis. HE is the commonest cause of death in patients with chronic liver disease. A clearly defined precipitating factor is usually identified in most patients with $\mathrm{HE}$ and the reversal or control of these factors is a key step in the management.

In this study, 50 patients of CLD presenting with hepatic encephalopathy were studied in a Tertiary Hospital, all possible important factors which could be responsible for precipitation or aggravation of hepatic encephalopathy were looked for and analyzed.

In our study, Male (72\%) outnumbered the female patients $(28 \%) \&$ with the majority of the patients age $(68 \%)$ above 40 years which is more consistent with kumar et al. ${ }^{12}$ Majority of patients in this study were from rural areas and belongs to poor socioeconomic group. The negative aspect for the rural population is that they reached tertiary care hospital in late phase. In this study, the majority of patients were in stage III coma $26(52 \%)$ while $11(22 \%)$ stage IV, $9(18 \%)$ stage II and $4(8 \%)$ stage I coma. Different studies shows encephalopathy from grade I to grade IV with diverse frequency. ${ }^{13-17}$

Amongst the clinical features, jaundice $(100 \%)$, altered conscious state $(100 \%)$, splenomegaly $(90 \%)$ and ascites $(100 \%)$ were the most common presenting features in patients with hepatic encephalopathy. Congregation of all these bad prognostic signs is of no surprise if the decompensated chronic liver disease of these selected patients is taken into account.

In this study, Gastrointestinal bleeding is the most important precipitating factor of HE $(28 \%)$ cases which is more consistent with Kumar et al $(39 \%)^{18}$ where Maqsood et al $2^{\text {nd }}$ most cause ${ }^{1}$, kumar et $\mathrm{al}^{12}$ shows $3^{\text {rd }}$ most common cause.

Infections were the second (26\%) most common precipitating factor of hepatic encephalopathy in this study. Kumar et al, Devrajani et al ${ }^{12}$, Maqsood et al ${ }^{1}$, Alam et $\mathrm{al}^{19}$, found it in $67 \%, 58 \%, 44 \%, 24 \%$ of their cases respectively. Souheil found infections responsible in only $3 \%$ of cases. ${ }^{20}$ In another study by Conn infections were responsible in only $4 \%$ of cases. ${ }^{19}$ The high frequency of infections in this study was probably because of unhygienic conditions and poor nutritional status of the patients.

In our study, multiple factors (i.e. infection \& GI bleeding, infection \& constipation or Hypokalemia) were found in same patient as a cause of HE in $16 \%$ cases. Hypokalemia was found in $6 \%$ of cases as an isolated precipitating factor compared to study done by Alam et $\mathrm{al}^{13}$ in which drugs (diuretics, sedatives) and electrolyte imbalance (hyponatremia and hypokalemia) were found to be a leading cause which were very high. But, Suheil ${ }^{20}$ and Conn ${ }^{19}$ found electrolyte imbalance in $11 \%$ and $9 \%$ of cases respectively. If we included hypokalemia within mixed factor the proportion would be high. Hypokalemia in our study was mostly due to diarrohoea, vomiting and diuretics therapy. In our study, we did not find any documented or prescribed drug history that can precipitate hepatic encephalopathy.

Constipation was the least in the list of precipitating factors (4\%) in this study as isolated cause which was consistent with Souheil ${ }^{20}$ Fallon $^{21}$ and Conn ${ }^{19}$ reported constipation in $6 \%, 3 \%$ and $3 \%$ of their cases respectively. On the other hand, Sheikh et $\mathrm{al}^{22}$ Hameed et $\mathrm{al}^{23}$ and Alam ${ }^{13}$ found it in $36 \%, 52 \%$ and $32 \%$ of their cases respectively. This may be because of dietary restriction, poverty, lack of use or inappropriate dosing of lactulose.

In this study, no precipitating factors were found in significant proportion of cases $(20 \%)$ in contrast to Maqsood et al where no precipitating factor of hepatic encephalopathy were found in $10 \%$ of cases. ${ }^{1}$ Higher proportion of unknown factors might be due to injudicial intake of drug from pharmacy without prescription, lack of knowledge regarding his/her disease, poverty, illiteracy, communication gap between Doctor-Patient \& last of all, due to economical constraint we could not do some important investigation in some patient.

In our study, mortality rate was $32 \%$ which was consistent with $30 \%$ in Maqsood et al; All chronic liver disease patients who expired were found to be in Class $\mathrm{C}$ of Child's Classification. (in this study 64\% patients were Child-pugh class C \& rest 36\% patients were Child-pugh class B). ${ }^{24}$

\section{Conclusions:}

Commonest precipitating factors of hepatic encephalopathy in this study were upper G.I. bleeding, infection, mixed factor and electrolyte imbalance. To prevent hepatic encephalopathy in chronic liver disease patients, caution must be exercised in putting chronic liver disease patient 
on diuretics. Early and effective infection control measures and better hygienic conditions in government hospitals are needed to be maintained. Consistent use of lactulose and fiber should be encouraged to prevent constipation. More and urgent endoscopic facilities should be made available nationwide for prompt control of gastrointestinal bleeding, and most importantly. Implementation of an effective screening program for early HBV detection all over the country should be on top of the official health concerns.

Conflict of interest: None.

\section{References:}

1. Maqsood S, Saleem A, Iqbal A, Butt JA. Precipitating factors of Hepaticenc ephalopathy. J Ayub Med Coll Abottabad 2006;18(4):57-60.

2. Ferenci P. Hepatic Encephalopathy. In Haubrich WS, Schaffner F, Berk JE, editors. Gastroenterolgy. $5^{\text {th }}$ edition. Philadelphia: W.B. Saunders; 1995:1988-2003.

3. Butterworth RF. The neurobiology of hepatic enc ephalopathy. Semin Liver Dis 1996;16:235-44.

4. Mahtab MA, Rahman S, Karim MF, Khan M, Foster G, Solaiman S, Afroz S: Epidemiology of hepatitis B virus in Bangladeshi general population. Hepatobiliary Pancreat Dis Int 2008;7:595-600.

5. Amodio P, Del Piccolo F, Marchetti P. Clinical features and survival of cirrhotic patients with subclinical cognitive alterations detected by the number connection test and computerized psychometric tests. Hepatology 1999;29:1662.

6. Watanabe A. Portal-systemic encephalopathy in non-cirrhotic patients: classification of clinical types, diagnosis and treatment. J. Gastroenterol. Hepatol. 2000;15:969.

7. Sherlock S, Dooley J. Hepatic Encephalopathy. In: Disease of the liver and biliary system. 11th edition. London:Blackwell Science; 2002:93.

8. Lizardi-Cervera J, Almeda P, Guevara L, Uribe M. Hepatic encephalopathy: a review. Ann Hepatol. 2003;2(3):122-30.

9. Conn HO. Effects of high-normal and low-normal serum potassium levels on hepatic encephalopathy: facts, half-facts or artifacts? Hepatology 1994;20:1637.

10. Batki G, Fisch HU, Karlaganis G, Minder C, Bircher J. Mechanism of the excessive sedative response of cirrhotics to benzodiazepines. Model experiments with triazolam. Hepatology 1987;7:629.

11. Hazell AS, Butterworth RF. Hepatic encephalopathy: an update of pathophysiologic mechanism. Proc. Soc. Exp. Biol. Med. 1999;222:99.

12. Kumar D, Devarajani BR, Zulfiqur S, Devarajani T: Precipitating Factors of Hepatic encephalopathy at a tertiary care hospital Jamshoro, Hyderabad. JPMA 59:683;2009.

13. Durrani AB, Rana AB Siddiqi HS, Marwat BU. The spectrum of chronic liver disease in Balochistan. J Coll Physician Surg Pak 2001;11(2):95-97.

14. Zakaria M, Hussain SR, Rehman M, Butt A, Rana GF. Hepatic encephalopathy; precipitating factors in patients with cirrhosis. Professional Med J. 2008;15(3):375-9.

15. Ali SA, Donahueb RMJ, Qureshi H, Vermund SH. Hepatitis B and hepatitis C in Pakistan: prevalence and risk factors. Int J Infect Dis 2009;13(1):9-19.

16. Alam I, Razaullah, Haider I, Humayun M, Taqweem MA, Nisar M. Spectrum of Precipitating factors of Hepatic Encephalopathy in liver cirrhosis. Pak J.Med. Res 2005;44 (2):96-100.

17. Tariq M, Iqbal S, Khan N, Basri R.Precipitating factors of hepatic encs ephalopathy Rawal Med J 2009;34(1):95-7.

18. Dileep K. Rohra, Jaipal, Ameer A. Khowaja, Mahmood K, Ahuja KL: Precipitating Factors of Hepatic Encephalopathy in Patients with Chronic Liver Disease at Civil Hospital Karachi, August 2006; 4(1):P27-35.

19. Conn HO, Leiberlhal MM. The hepatic coma syndrome and lactulose $1^{\text {st }}$ edition. Baltimore: William and Wilkins 1980:106.

20. Souheil Abu-Assi, Vlaeevie ZR. Hepatic encephalopathy Metabolic consequences of the cirrhosis are often reversible. Postgraduate Med 2001;10.

21. Faloon WW, Evans GL. Precipitating factors in the genesis of hepatic coma. NY Stage J Med 1970;70:2891.

22. Shiekh S. Portal systemic encephalopathy in cirrhotic liver disease. Experience at People Medical College, Nawabshah J Coll Physican Surg Pak 1998;8:53.

23. Ahmed H, Rehman MU, Saeedi I, Shah D. Factors precipitating hepatic encephalopathy in cirrhosis liver. Postgrad Med Inst 2001;15(1):91-7.

24. Child-Turcotte-Pugh (CTP) classification of the severity of cirrhosis. Available from: https://www.hepatitis.va.gov/pdf/Child-Pugh-score.pdf. Accessd on 04 November, 2016. 